\title{
Políticas editoriales aprobadas por la Junta Directiva del Consejo de Editores Científicos ${ }^{1}$
}

\author{
Consejo de Editores Científicos
}

Forma de citar

Consejo de Editores Científicos. Políticas editoriales aprobadas por la Junta Directiva del Consejo de Editores Científicos [Editorial policy statements approved by the CSE Board of Directors]. Rev Panam Salud Publica. 2004;16(1):52-61.

\section{POLÍTICA EN TORNO A LAS RESPONSABILIDADES $Y$ DERECHOS DE LOS EDITORES DE REVISTAS CON ARBITRAJE CIENTÍFICO}

Los directores de revistas científicas -los jefes de redacción y otros editores

\footnotetext{
Esta es una traducción de "Editorial policy statements approved by the CSE Board of Directors," declaración emitida por la Junta Directiva del Consejo de Editores Científicos, cuya sede está en
}

La presente traducción al castellano forma parte de una serie que la Revista Panamericana de Salud Pública y su precursor, el Boletín de la Oficina Sanitaria Panamericana, vienen publicando desde hace varios años con miras a poner al alcance de investigadores y editores hispanoparlantes las principales fuentes autorizadas que sientan pautas en el campo de la investigación y publicación científicas en el mundo. Sobresalen en este empeño la publicación por entregas de la obra clásica Cómo publicar un trabajo científico, de Robert A. Day, las sucesivas ediciones de las afamadas normas de Vancouver y "Las buenas prácticas de publicación: recomendaciones para compañías farmacéuticas", de Wager, Field y Grossman.

El Consejo de Editores Científicos (Council of Science Editors, CSE), cuya sede está en Reston, Virginia, Estados Unidos de América, es una entidad profesional internacional que publica y disemina información en materia de publicación científica. Su Comité de Politicas Editoriales periódicamente examina las politicas editoriales vigentes en el mundo y emite sus propias recomendaciones, orientadas a impartirles mayor definición y claridad a aquellas. En su reciente declaración titulada "Editorial policy statements approved by the CSE Board of Directors", cuya traducción se presenta en las siguientes páginas, el Comité de Políticas Editoriales del CSE se pronuncia acerca de las funciones, obligaciones y responsabilidades de cada una de las personas o entidades que participa en la revisión, edición y publicación de los manuscritos presentados a revistas científicas. que participan en la definición de políticas, incluidos los que se especializan en distintas materias - tienen la responsabilidad de asegurarse de que el contenido de sus publicaciones sea de calidad, es decir, exacto, válido, fiable, verosímil, autorizado, compatible con el alcance y la misión de la revista, le-

Reston, Virginia, Estados Unidos de América. El texto original en inglés puede consultarse en www. councilscienceeditors.org gible y fácil de entender. Como es raro que hoy en día los científicos jóvenes reciban tutelaje de sus colegas más expertos, quienes antaño los orientaban sobre la marcha en materia de publicación, los directores de revistas ahora se ven obligados a dar indicaciones muy específicas sobre la manera de comunicar información científica en sus revistas. Esto se aplica a asuntos tales como la autoría, los conflictos de intereses, las normas éticas, y demás. Los edito- 
res de revistas deben tratar todos los materiales que reciben sin prejuicios, uniformemente y con la rapidez debida, procurando evitar que haya parcialidad, conflictos de intereses y presiones externas a la hora de tomar decisiones editoriales. En el cumplimiento de sus obligaciones, los directores tienen responsabilidades particulares con los autores, lectores y árbitros. Para poder cumplir con sus distintas tareas, que a menudo compiten unas con otras, y para atender a lo que le exigen otras personas y grupos (tales como los propietarios de la revista, la editorial, las agencias de publicidad, las cadenas noticieras y las agencias gubernamentales), el director de una revista debe tener libertad editorial basada en su autoridad y autonomía.

\section{¿Cuáles son las responsabilidades del director de una revista científica?}

\section{Responsabilidad de la calidad del contenido}

Los directores de revistas poseen una variedad de conocimientos y recursos propios, así como ajenos, que los ayudan a garantizar la calidad del contenido de sus publicaciones. El editor que está en posición de tomar decisiones (a quien se le suele conocer por "Jefe de Redacción o Director") debe poseer experiencia y conocimientos en el campo al que está dedicada la revista. A la mayoría de los directores de revistas se les escoge por haber hecho aportes importantes a sus disciplinas, más que por sus conocimientos en materia de publicación. Sin embargo, a veces el haber publicado anteriormente y haber formado parte de una junta editorial, así como el tener conocimientos de metodología científica y estadística y buenas facultades críticas y analíticas, pueden ser factores para que un científico sea un mejor director de revista que otro de igual formación pero sin ninguna experiencia editorial, aunque goce de más prestigio en el gremio de su disciplina científica.

Los directores de revistas deben escoger trabajos que sean novedosos y originales y que aporten conocimientos importantes; que presenten resultados válidos y repetibles en suficiente detalle para que los lectores puedan valorar la validez de las inferencias; que tengan lógica y coherencia y hagan debida mención de trabajos anteriores. Sean o no expertos en la temática de la revista, deben apoyarse en los conocimientos de otros editores, asesores y árbitros. Aunque su número y su compromiso varían según el tamaño de la revista, estos expertos pueden ayudar a definir políticas, solicitar y revisar manuscritos, escribir editoriales y hasta dirigir departamentos particulares de la revista. El director también se apoya en árbitros, que son expertos en los temas tratados en los trabajos, para que le proporcionen evaluaciones críticas de la precisión, fiabilidad y validez de estos. Los directores también dependen de asistentes editoriales y correctores de estilo para mejorar los aspectos sustantivos y técnicos de los trabajos aceptados, asegurándose de que estos tengan corrección gramatical, coherencia estilística y terminológica, precisión y legibilidad.

Los directores de revistas deben definir claramente y poner en práctica las normas éticas de la revista (por ej., las referentes a la publicación duplicada, a los sujetos de investigación, etc.). Aunque el director debe estar atento a posibles violaciones de estas normas, no es su cometido investigar, juzgar o castigar a los autores que cometen infracciones. El Consejo de Editores Científicos (Council of Science Editors, CSE) ha recomendado que cada revista establezca una política acerca de la responsabilidad del director de notificar a la institución a la que está afiliado un autor cuando este no acata las normas éticas de la revista. El director también tiene la responsabilidad de informar a los lectores y servicios secundarios cuando se descubre formalmente que ha habido plagio, invención o falsificación de datos.

Los directores de revistas deben establecer procedimientos para velar por la calidad de la revista, identificar errores y problemas, detectar tendencias que reflejen un deterioro de la calidad y poner en marcha acciones co- rrectoras según sea necesario. Cualquier error en un artículo publicado debe darse a conocer mediante una nota de corrección o fe de errata. Los directores de revistas deben llevar la cuenta del número y tipo de errores que se producen en sus revistas; un repaso formal, retrospectivo y cualitativo de cada número ayuda a los directores a monitorear la calidad de sus revistas. Este repaso puede consistir simplemente en entregarles un ejemplar a todas las personas con alguna injerencia en el contenido editorial y el proceso de producción y pedirles que pongan en él sus críticas y comentarios para que todos los vean.

Los directores de revistas también deben encargarse de llevar un control de los plazos fijados a lo largo del proceso de edición y producción (plazos de entrega en cada etapa, desde que el manuscrito se recibe hasta que se publica). Conocer estos datos y tendencias puede ayudar a los directores de revistas a controlar los porcentajes de aceptación y rechazo de ciertos tipos de manuscritos, llevar un inventario de los manuscritos aceptados, observar el rendimiento de los árbitros y determinar las necesidades de personal. Algunas revistas publican datos de auditoría anuales, entre ellos el número total de manuscritos recibidos, el porcentaje de aceptaciones y el tiempo promedio que se lleva procesar cualquier manuscrito, sea aceptado para publicación o rechazado. Esta información le permite al director cumplir con algunas de sus responsabilidades con los lectores enumerados a continuación. Una nota con las fechas de recepción y aceptación cuando se publica un artículo también provee información que es útil para los autores y lectores.

Por último, los directores de revistas tienen la responsabilidad de observar las normas de publicación y los procedimientos establecidos por su organización patrocinadora, así como los términos particulares que puedan especificarse en su contrato con esa entidad. Se entiende que esto abarca el manejo responsable de la revista desde el punto de vista fiscal y la adhesión al calendario de publicación establecido. 
Responsabilidades de los directores de revistas con los autores

Los directores de revistas deberán:

- Tratar a los autores con justicia, cortesía, objetividad y honradez.

- Tomar decisiones y responder a las preguntas de los autores en un plazo oportuno.

- Proteger la integridad y confidencialidad del trabajo de cada autor.

- Fijar e imponer una política sobre los conflictos de intereses para autores, editores y árbitros.

- Describir un proceso de apelación para autores.

- Describir un proceso para responder a acusaciones de conducta inapropiada por parte de autores.

- Proveer una guía para la preparación y presentación de manuscritos.

- Seleccionar pares adecuados y preparados para que revisen cada manuscrito enviado a arbitraje y estar a cargo del proceso de revisión.

- Establecer estándares para los árbitros, procurando proteger el carácter confidencial de los manuscritos, fijar plazos de entrega prudentes y que los árbitros aporten referencias para documentar sus comentarios críticos sobre las deficiencias de los manuscritos.

- Velar por que los procesos editoriales relacionados con el arbitraje científico se lleven a cabo con justicia, rapidez, minuciosidad y cordialidad.

Responsabilidades de los directores de revistas con los lectores

Los directores de revistas deberán:

- Velar por la calidad del contenido de la revista, procurando que cada artículo les proporcione a los lectores las pruebas que necesitan para evaluar las conclusiones de los autores y poder fiarse de lo que leen.

- Pedirles a todos los autores que revisen el borrador final de su trabajo y que se hagan responsables de él; podría pedirse la firma del autor a cargo de la correspondencia solamente, o bien la de todos los autores.
- Mantener la integridad interna de la revista (por ej., separar o de algún modo identificar el contenido científico, editorial y propagandístico).

- Revelar las fuentes (autores, propietarios, patrocinadores y demás).

- Separar las investigaciones y revisiones sometidas a arbitraje de los trabajos de opinión, y apartar el contenido editorial de los anuncios y otro material propagandístico.

- Ofrecer una sección para cartas que permita a los lectores responder y debatir (muy recomendable aunque no indispensable).

- Crear mecanismos para determinar si la revista está satisfaciendo las necesidades y expectativas de los lectores (encuestas).

Responsabilidades de los directores

de revistas con los árbitros

Los directores de revistas deberán:

- Asignar trabajos para revisión según el campo de interés y la especialidad de los árbitros.

- Darles a los árbitros suficiente tiempo para completar sus revisiones.

- Darles a los árbitros instrucciones explícitas por escrito acerca de lo que la revista espera en cuanto al contenido, la calidad y el tiempo de entrega de sus evaluaciones.

- Porporcionarles a los árbitros guías y normas (preferiblemente por escrito) conducentes a que hagan revisiones bien razonadas, justas, constructivas e informativas que faciliten el manejo eficiente y rápido de los trabajos.

- Encontrar maneras de reconocer las contribuciones de los árbitros mediante una sección ocasional de agradecimiento público en la revista, o proporcionándoles cartas que puedan servirles a la hora de solicitar promociones académicas.

\section{¿Qué derechos tienen los directores de revistas?}

\section{Derechos de los directores de revistas}

Para establecer y mantener un contenido de calidad, el director debe tener derecho cuando asume su cargo a recibir del propietario de la revista una declaración escrita que defina sus derechos y su autonomía. El derecho del director a gozar de libertad editorial debe tener el respaldo de los siguientes, por mutuo acuerdo entre el director y el propietario de la revista:

- Una declaración de la misión de la revista.

- Prioridades editoriales formuladas por escrito.

- Políticas editoriales formuladas por escrito.

- Una descripción escrita del cargo, con pormenores acerca de la libertad editorial que tiene el director en lo referente a la aceptación y publicación de trabajos originales, el grado de control del contenido propagandístico, etc.

- Una junta editorial nombrada por el editor y responsable ante él.

- Vías de comunicación directa con la editorial de la revista, su propietario o ambos.

- Apoyo suficiente de la sociedad auspiciadora, la editorial, el propietario $\mathrm{u}$ otro patrocinador en cuanto a los recursos monetarios y humanos necesarios para llevar a la práctica la misión de la revista.

- De preferencia, un mecanismo para que la organización auspiciadora evalúe periódicamente y de manera objetiva el trabajo del director de la revista.

\section{POLÍTICA EN TORNO AL ACCESO DE LA REVISTA A INFORMACIÓN CIENTÍFICA}

Para evaluar un manuscrito a veces se necesita tener acceso a datos y análisis que no se proporcionan en el manuscrito presentado, y en ocasiones ese acceso también es necesario después de la publicación. Los directores de revistas deben establecer políticas que contemplen los siguientes aspectos de este acceso:

Las organizaciones que patrocinan la investigación deben fomentar la publicación de resultados y proporcionar acceso a datos si los piden las revistas para 
fines del arbitraje científico. Las organizaciones patrocinadoras podrían limitar el acceso a los datos durante la investigación y aun después de que esta haya terminado, pero no tienen derecho a controlar la diseminación o interpretación de los resultados de la investigación. Tienen el deber de proporcionar acceso a cualquier dato que se necesite para llevar a cabo el arbitraje.

La presentación de un manuscrito original a una revista lleva implícito el consentimiento para proporcionar acceso a los datos necesarios para la evaluación editorial y el arbitraje científico. Las revistas también deben tener derecho a revisar los datos en los que se basan los manuscritos que salen publicados, en caso de que surjan interrogantes acerca de la validez del trabajo o la posibilidad de que contenga errores. Este derecho de la revista a tener acceso a los datos debería ser expresada por los directores en la versión publicada de sus políticas editoriales y en las instrucciones para los autores.

Los directores de revistas deben pedir acceso a datos para el propósito exclusivo de evaluar un manuscrito presentado para publicación o cuando se disputa la validez de un trabajo después de que se ha publicado. Los directores, árbitros y el personal de la revista deberán respetar la confidencialidad de los datos y abstenerse de usarlos para fines personales o de beneficiarse directamente del acceso a ellos que les facilita su condición de árbitros.

\section{POLÍTICA EN TORNO AL AVISO DE POSIBLES VIOLACIONES DE LA CONDUCTA ÉTICA}

Por lo general, cualquier sospecha de que se han violado las normas éticas de la publicación científica se le comunica primero al director de una revista en relación con un manuscrito que ha sido presentado o que ya se ha publicado. Muchas revistas carecen de una política uniforme para hacer frente a este tipo de quejas, aunque todas deberían establecer una política de esta naturaleza y colocar en las instrucciones para los autores un párrafo que rece así:
"En caso de sospecharse o determinarse que ha habido conducta poco ética o deshonesta por parte del investigador en un trabajo enviado a arbitraje, esta redacción se reserva el derecho de enviarle el manuscrito a la institución patrocinadora o financiadora o a otra autoridad pertinente para que se lleve a cabo una investigación. Nuestra redacción reconoce su responsabilidad de asegurarse de que el asunto se investigue debidamente, pero no es ella quien emprende la investigación ni quien determina si se ha cometido una infracción de la ética". (Uniform requirements. Ann Int Med 1997 126(1):45).

\section{LOS CONFLICTOS DE INTERESES Y EL PROCESO DE ARBITRAJE CIENTÍFICO}

\section{Objetivo}

Proporcionar normas que les sean útiles a las revistas biomédicas a la hora de definir políticas y procedimientos en conexión con los conflictos de intereses en el arbitraje científico.

\section{Definición}

Un diccionario de inglés muy conocido (Webster's 9th New Collegiate Dictionary) define los conflictos de intereses como "conflictos entre los intereses personales y las responsabilidades oficiales de una persona que ocupa un cargo de confianza". En el campo de la publicación científica, el autor de un manuscrito, el árbitro y el director de la revista son, sin excepción, personas que ocupan "cargos de confianza".

Los conflictos de intereses en el ámbito editorial pueden definirse como un conjunto de circunstancias en las cuales un autor, director de revista o árbitro tiene intereses que entran en conflicto o compiten entre sí y que podrían redundar en parcialidad o en decisiones inapropiadas. Los conflictos de intereses pueden ser potenciales o tan solo percibidos, sin necesidad de que sean tan siquiera potenciales.

La determinación de que existe un conflicto de intereses puede ser suma- mente difícil y a menudo contenciosa. Suele ser más fácil percatarse de la posibilidad de que haya un conflicto de intereses; estos conflictos se producen con frecuencia y lo que preocupa no es el hecho de que existan, sino que puedan dar lugar a parcialidad o pasar desapercibidos. Este tipo de situación, reflejo de una falta de sensibilidad frente a la posibilidad de un conflicto de intereses, es alarmante, independientemente de que se produzca en un autor, árbitro o director de revista.

Lo ideal sería que los autores fuesen completamente objetivos a la hora de presentar sus resultados y que los directores de revistas y árbitros fuesen absolutamente objetivos al evaluarlos. Todos estos procesos están sujetos a sesgos. Consideraciones de carácter personal, político, económico, académico o religioso pueden menoscabar a la objetividad de mil maneras. Para los autores, directores de revistas y árbitros la dificultad radica en saber reconocer la posibilidad de un sesgo como resultado de un conflicto de intereses y obrar en consecuencia.

\section{Conflictos económicos}

El tipo más obvio de conflicto de intereses económico es aquel en que un producto comercial está en estudio y el autor, árbitro o director de la revista puede beneficiarse económicamente, si la evaluación del producto da ciertos resultados. Por ejemplo, un autor que describe la investigación de un producto en particular siendo a la vez propietario de acciones en la compañía que fabrica el producto, claramente podría sacar una ventaja económica directa si la evaluación fuese favorable. Un investigador empleado por una empresa con fines de lucro tiene un vínculo un poco menos directo con la investigación en torno a un producto, pero aun así es razonable suponer que pueda beneficiarse si al producto le va bien. En estos ejemplos, los "intereses particulares" de una persona (es decir, sus intereses económicos) podrían estar en pugna con sus "responsabilidades oficiales" (es decir, la responsabilidad del científico de aspirar a conocer la verdad). 
Es un poco distinta la situación cuando un investigador estudia un producto fabricado por una empresa con fines de lucro de la cual ha recibido dinero anteriormente (por ej., por una consultoría o en forma de honorarios o remuneración por una charla). En este caso no hay ninguna conexión directa entre la evaluación y algún lucro personal que el investigador pueda esperar. No obstante, es concebible que el haber recibido dinero, aunque haya sido en otro momento, influya en el resultado de la investigación y por lo tanto debe considerarse una posible fuente de conflicto de intereses.

Los ejemplos aquí citados se aplican a autores que presentan los resultados de sus investigaciones, a artículos que no son de investigación, a revisiones bibliográficas y a artículos de opinión, pero también podrían aplicarse a árbitros que evalúan un manuscrito o a directores de revistas que deben decidir si un manuscrito se acepta o se rechaza. Hay diferencias sutiles entre autores, árbitros y directores de revistas en lo concerniente a intereses económicos, pero los principios básicos son los mismos en todos los casos.

Algunas redacciones de revistas se niegan a aceptar manuscritos que describen el estudio de un producto comercial cuando la investigación ha sido financiada por una empresa comercial vinculada con la fabricación o venta del producto. Algunas revistas no publican ni editoriales ni artículos de revisión de autores con posibles conflictos de intereses de tipo económico, por considerar que estos escritos, por su naturaleza, se basan mucho en la interpretación y el juicio personales, de tal manera que la presencia de un conflicto de intereses y la posibilidad de un sesgo plantean en esos casos un problema todavía mayor.

\section{Conflictos que no son de carácter económico}

Los "intereses particulares" pueden ser de muy diverso orden, entre ellos el intelectual, político, académico y religioso. Lo importante es que los autores, árbitros y directores de revistas se percaten de la posibilidad de que se presenten conflictos de esta naturaleza, además de los de tipo económico, y que actúen en consecuencia. Tener una objetividad absoluta no siempre es posible, pero cabe al menos esperar que haya justicia y ecuanimidad. Por ejemplo, si un árbitro se opone al aborto por razones religiosas o morales, puede que le cueste revisar con objetividad un manuscrito donde se describe el uso de tejidos fetales para fines de investigación. O puede ser que el director de una revista, siendo a la vez jefe de un departamento académico, tenga dificultad en tomar decisiones objetivas en torno a manuscritos preparados por miembros del claustro de su departamento porque, en su condición de jefe, el director tiene un "interés particular" en el éxito académico de estos.

\section{La divulgación de información}

La clave para detectar y saber manejar los conflictos de intereses, sean o no de carácter económico, radica en su divulgación: al director de la revista cuando se presenta el manuscrito, y al lector cuando el trabajo se publica. Lo primero permite que a la hora de evaluar el manuscrito el director de la revista esté enterado de todas las circunstancias que lo rodean, y lo segundo, que el lector tenga a su disposición suficiente información para interpretar el trabajo adecuadamente.

Divulgar un posible conflicto de intereses tiene por objeto mantener la integridad del juicio profesional y la confianza del público en él. La divulgación no ha de tomarse como indicio de que los científicos se han visto indebidamente influenciados por la posibilidad de lucrar. Más bien, en estos casos la divulgación les ofrece a los lectores la información que necesitan para poder tomar decisiones con conocimiento de causa, ya que a menudo es difícil determinar en qué casos la investigación se ha llevado a cabo bajo la influencia indebida de un afán de lucro. Informar a los lectores es responsabilidad de la revista. Algunos podrían argumentar, sin embargo, que la divulgación obligatoria de las fuentes de financiamiento se basa en la premisa equivocada de que las consideraciones de tipo económico son las únicas que influyen en los autores y de que todos los autores se dejan influenciar. Podrían pensar, además, que la divulgación crea en el lector un prejuicio injusto contra el autor. (Véase Rothman J.J. Conflict of interest: the new McCarthyism in science. JAMA 1993 269:2782-4.)

\section{Autores}

Muchas revistas exigen que se indique la fuente de financiamiento de un estudio dentro del manuscrito presentado para publicación. He aquí algunos ejemplos sacados de la sección de "Instrucciones para los autores" de distintas revistas: en la lista de requisitos para la presentación de manuscritos a la revista Science se pide que se dé "cualquier información acerca de las afiliaciones profesionales o económicas de los autores que puedan percibirse como fuentes de parcialidad en la presentación". Journal of the American Medical Association (JAMA) les exige a los autores que firmen una declaración dando a conocer "toda afiliación o relación financiera con organizaciones o entidades que tengan un interés económico directo en el tema o material examinado en el manuscrito (por ej., empleo, consultorías, propiedad de acciones, honorarios, testimonio profesional ante un jurado, patentes emitidas o pendientes). Obstetrics and Gynecology emplea palabras muy semejantes y especifica un plazo límite de tres años. En la mayor parte de los casos, las políticas de las revistas establecen que los autores deben divulgar cualquier interés económico pertinente cuando presentan su manuscrito. A partir de ese momento el director de la revista tiene la responsabilidad de interpretar esta información y, si el trabajo se acepta posteriormente, de decidir si la información debe transmitírsele al lector o no y de qué manera.

Durante el proceso de arbitraje, ¿cómo debe manejarse la divulgación de intereses económicos por parte de los autores? Las revistas difieren en sus políticas al respecto. Algunas les 
proporcionan la información a los árbitros y les piden que se encarguen de evaluarla, junto con los méritos científicos del trabajo. En tales casos las opiniones de los árbitros acerca de los intereses económicos de los autores podrían pesar mucho en la decisión del director de la revista y dar lugar a cierto tipo de parcialidad editorial. Otras revistas se adhieren a lo recomendado por el Comité Internacional de Directores de Revistas Médicas (CIDRM) y no divulgan esa información durante el proceso de arbitraje, pidiéndole al director de la revista que la tenga en cuenta (quizá con la ayuda de un evaluador externo también) solamente después de que se ha evaluado el mérito científico. Este último modo de proceder posee la ventaja de que el asunto se divide en fases claramente identificables.

Los lectores tienen derecho a saber si existe la posibilidad de un conflicto de intereses. Las consideraciones que más preocupan a las revistas son de tipo económico, y estas, por lo general, son las más fáciles de divulgar. No obstante, los conflictos de intereses económicos no se detectan con facilidad sin que se revelen los hechos. Tales conflictos se dan por cuestiones de salarios, pagos y honorarios por consultorías, interés en acciones o capital y derechos de propiedad intelectual (patentes, regalías y derechos de autoría). La mayoría de las revistas les piden a los autores que revelen cualquier posible conflicto de intereses de tipo económico que puedan tener en relación con el tema tratado en sus manuscritos. Algunas les piden que den a revelar todo interés económico con cualquier entidad que pudiese afectar a su trabajo.

Los autores tienen la responsabilidad de declarar estos posibles conflictos de intereses. Las revistas no investigan la presencia de estos últimos y no se espera que vigilen la conducta de los autores. Sin embargo, los directores de revistas deben estar atentos a la posibilidad de que se produzcan conflictos de intereses porque puede ser que los autores no los declaren. Si un autor no declara determinado interés económico, se produce incompatibilidad con el derecho de los lectores a conocer esta po- sible fuente de sesgo. Este tipo de información puede ayudar a los lectores a decidir si un patrocinio determinado ha ejercido una influencia indebida sobre el investigador y si los resultados de la investigación no son los que habrían sido en otras circunstancias.

\section{Ejemplos de declaraciones de intereses}

Journal of the American Medical Association exige que se divulgue la presencia de intereses económicos en la sección titulada "Authorship criteria and responsibility, financial disclosure, assignment of copyright, and acknowledgment" [Criterios de autoría y responsabilidades de los autores, divulgación de intereses económicos, asignación de derechos de autor y agradecimientos].

"Declaración de intereses: Certifico que a continuación se explicita toda afiliación económica o de otra índole, con cualquier organización o entidad que tenga un interés económico en los materiales examinados en el manuscrito (i.e., trabajo, consultorías, propiedad de acciones, honorarios, prestación de testimonio ante un jurado). Todas las fuentes de financiamiento de este proyecto de investigación se identifican en la sección de agradecimientos del manuscrito."

Obstetrics and Gynecology les exige a los autores que firmen un formulario, que se adjunta al manuscrito cuando este se presenta a la revista, donde aparece una sección para la divulgación de intereses económicos: "Afirmo que en los últimos tres años no he tenido ninguna afiliación económica (i.e., trabajo, propiedad de acciones, consultorías $\mathrm{u}$ honorarios) con ninguna organización que tenga un interés económico directo en el asunto o en los materiales examinados en este manuscrito, salvo por las que figuran en el anexo".

En su lista de requisitos para la presentación, Science pone lo siguiente: "Proporcione junto con su manuscrito: ... cualquier información acerca de las afiliaciones profesionales o económicas de los autores que puedan percibirse como fuentes de sesgo en la presentación de los resultados".
Algunas revistas (por ej., New England Journal of Medicine y Obstetrics and Gynecology) no permiten que los autores de editoriales o artículos de revisión bibliográfica tengan ningún conflicto de intereses económico, ya que estos textos analíticos dependen mucho de la interpretación y el criterio individuales. Se considera difícil que los lectores pueden detectar conflictos de intereses en los artículos de opinión.

Hay por lo menos una revista (Obstetrics and Gynecology) que divulga los conflictos de intereses dentro de un recuadro en la primera página del manuscrito publicado. Cuando el director de una revista estima que se debe dar a conocer un conflicto de intereses de tipo económico, él o ella le avisa al autor encargado de la correspondencia y le explica cómo debe redactarse la "declaración de intereses económicos". Esta situación se puede presentar cuando cualquiera de los autores tiene vínculos financieros con un producto o una compañía en particular y el artículo pudiera interpretarse como un respaldo a ese producto o compañía. El manuscrito se aceptará bajo la condición de que el autor consienta en hacer la divulgación.

\section{Los árbitros}

Los conflictos de intereses que afectan a los árbitros no solo se producen por motivos económicos, sino también por rivalidad, competencia académica en materia científica y tecnológica, y valores y creencias ideológicas. Cuando se pide a los árbitros que revisen un manuscrito, se les debe explicar específicamente en qué consiste un conflicto de intereses. Precisamente porque son expertos en el tema examinado (es decir, pares del autor), los árbitros son propensos a tener conflictos de intereses, tanto económicos como de otra índole. Por consiguiente, el problema no es que haya un conflicto, sino que el conflicto tenga suficiente peso para minar la capacidad del árbitro de evaluar el manuscrito con justicia y objetividad. Las revistas deben pedirles a los árbitros que se descalifiquen a sí mismos si sienten que no pueden hacer 
una evaluación justa y objetiva. Si los árbitros tienen preguntas en este sentido, se les debe insistir en que hablen con el director de la revista.

La mayor parte de las revistas, al abordar este asunto, dan una orientación bastante general e inespecífica. No obstante, JAMA les pide a los árbitros que llenen una sección del formulario de revisión donde se divulga cualquier posible conflicto de intereses. Esto obliga al árbitro a prestar atención al asunto y a declarar de manera explícita que no tiene conflictos de esta naturaleza.

Algunos árbitros opinan que hay un conflicto si ya han revisado el mismo manuscrito para otra revista. Si el árbitro aún considera que el manuscrito se puede revisar con objetividad, muchos directores de revistas prefieren mandarle el manuscrito al mismo árbitro, quien está en posición de juzgar si el manuscrito ha sido mejorado.

\section{Los directores de revistas}

El director de la revista tiene la responsabilidad de establecer y mantener las más altas normas de calidad en lo que respecta a las contribuciones que ocupan las páginas de la revista, y de mantener la integridad de esta última. $\mathrm{Su}$ principal responsabilidad radica en garantizar que el arbitraje de los manuscritos presentados para publicación sea justo, y es su deber considerar imparcialmente todos los manuscritos presentados. Los directores de revistas no deben tener ningún vínculo económico personal con los manuscritos cuya publicación contemplan. Un director de revista debe descalificarse a sí mismo como ente decisor cuando un manuscrito versa sobre un tema que le plantea un posible conflicto de intereses. Algunas revistas establecen que sus directores no pueden tener intereses económicos en ninguna empresa comercial que pudieran influir en la decisión de publicar un manuscrito. Otras revistas les piden a sus directores que firmen formularios de divulgación de intereses económicos cada año.

Los directores de revistas también deben apartarse a la hora de evaluar manuscritos presentados por colegas o amigos locales o que pugnan con sus ideas religiosas. Por ejemplo, el director de una revista puede optar por mantenerse al margen del proceso de arbitraje cuando se trata de un manuscrito redactado por un colega inmediato. En estos casos, el director de la revista, quien normalmente desconoce la identidad de los árbitros del manuscrito, suele pedirle a un editor invitado o asociado que se encargue del proceso de revisión. El editor invitado toma la decisión final acerca del manuscrito. Los directores de algunas revistas consideran que someter a arbitraje los manuscritos cuyos autores son miembros del consejo editorial de la revista constituye un conflicto de intereses y le piden a un editor invitado que se encargue del arbitraje de esos manuscritos. Los directores de revistas son, al fin y al cabo, seres humanos susceptibles a los mismos prejuicios $\mathrm{y}$ conflictos que los árbitros y autores.

\section{Recomendaciones}

El Comité de Políticas Editoriales recomienda que:

- Las revistas les pidan a los autores que declaren todas las fuentes de financiamiento de sus investigaciones y que pongan esta información en la sección de agradecimientos del artículo publicado.

- Las revistas les pidan a los autores que declaren otros posibles conflictos de intereses en la carta de presentación del manuscrito.

- Las revistas publiquen en el artículo las fuentes de financiamiento o apoyo. El director de la revista debe decidir si se incluye una descripción, junto con el artículo o la carta publicada, de todo el apoyo económico o de cualquier conflicto de intereses que estime deba revelarse a los lectores. La descripción debe publicarse en una nota al pie de la primera página del manuscrito.

- Las revistas deben tener una política que defina cómo han de manejarse los conflictos que han sido ocultados cuando una tercera entidad los detecta más tarde, y cómo darles una explicación a los lectores.

- Las revistas deben tener una política y un plan de acción en caso de haberse ocultado intereses económicos que se detectan después de la publicación. Los directores de revistas pueden optar por publicar una nota titulada "Intereses económicos no divulgados".

- Todos los autores, directores de revistas y árbitros deben divulgar cualquier posible conflicto de intereses. Los autores y árbitros deben dárselo a conocer al director de la revista; este último debe revelar sus posibles conflictos de intereses al comité de publicaciones o a su equivalente.

A nuestro parecer, es preferible pecar por exceso de divulgación que por defecto. Con la ayuda de los autores, los directores de revistas sabrán elegir la información que los lectores deben conocer en conexión con los posibles conflictos de intereses.

Plantéese la siguiente interrogante: "Si estos hechos no se divulgaran y más tarde salieran a la luz por algún otro medio, ¿serían motivo de bochorno o recriminación? Los lectores y los editores deben ser advertidos de cualquier posible conflicto de intereses a fin de que tengan a su alcance la información necesaria para tomar decisiones fundadas sobre la influencia que esos conflictos pudieran ejercer sobre el manuscrito".

\section{RELACIONES ENTRE LOS DIRECTORES DE REVISTAS Y SUS EDITORIALES O SOCIEDADES PATROCINADORAS}

\section{Declaración de principios}

Un editor científico reconoce que la ética en el campo científico y editorial se basa en la integridad, la competencia y la responsabilidad de proteger los intereses de la comunidad y del público. El editor científico debe fomentar la comunicación de los resultados de la investigación científica de un modo tal que se observen las normas 
más estrictas de fiabilidad, accesibilidad, transparencia e integridad en toda empresa científica, así como promover los intereses éticos y colectivos más generales de la ciencia en el dominio público.

\section{Relaciones entre el director de una revista y la editorial que la publica o la sociedad patrocinadora y su dirección}

i. El director de la revista tendrá la completa responsabilidad, autoridad y deber de rendir cuentas en conexión con el contenido editorial de la revista que dirige. Debe tener la libertad para autorizar que se publiquen trabajos de investigación y otros informes sometidos a arbitraje que sean apropiados, así como noticias acerca de la sociedad, anuncios adecuados y otros materiales, y no debe estar sujeto a interferencias unilaterales, políticas o arbitrarias en ningún otro sentido que pudiesen minar la larga tradición de libertad de prensa en el ámbito científico. Aunque la editorial o la sociedad patrocinadora y dirección suelen encargarse de las finanzas y otros aspectos administrativos, siempre reconocerán y aceptarán la integridad científica de la revista y la independencia editorial de su director.

ii. El director de la revista y la editorial o sociedad patrocinadora y los miembros de su dirección deberán firmar un contrato, en presencia de testigos, que garantice como es debido la libertad y responsabilidad editoriales. El contrato debe identificar a los miembros de la dirección, al comité o a cualquier otro grupo administrativo al que rinde cuentas directamente el director de la revista. También debe describir claramente las tareas propias de cada cargo, la persona a la que cada quién rinde cuentas y los criterios para evaluar el trabajo. Deben especificarse las expectativas de todas las partes en términos científicos, editoriales y administrativos, los términos de referencia con arreglo a los cuales se publica la revista, la longitud del contrato, las condiciones financieras, incluidos los gastos de funcionamiento y la remuneración (si la hay) y los términos en caso de rescisión del contrato por cualquiera de las partes.

iii. El director de la revista se conducirá de una manera profesional, sin prejuicios ni conflictos de intereses.

iv. A fin de mantener la autonomía relativa a la publicación de informes sometidos a arbitraje, el director de la revista no permitirá que sus criterios editoriales se vean influenciados por consideraciones políticas, comerciales o de otra índole que sean ajenas al contenido de cada informe científico y del análisis de sus posibles impactos y aplicaciones.

v. El director de la revista deberá informar a la editorial o sociedad patrocinadora de cualquier incidente político, comercial o de otra índole que pueda menoscabar la credibilidad científica de la publicación, y tomará las medidas necesarias para asegurarse de que tales incidentes no afecten a las decisiones que pueda verse obligado a tomar.

vi. El director de la revista, sea voluntario o empleado de plantilla a tiempo completo, dará a conocer anualmente a la editorial o sociedad patrocinadora y sus directores toda actividad científica ajena a sus tareas editoriales que haya emprendido.

vii. El director de la revista deberá asegurarse de que el arbitraje y otras tareas editoriales sean desempeñadas por expertos calificados según sea necesario, y de que estos especialistas divulguen cualquier conflicto entre sus intereses y los del director de la revista, los autores del manuscrito presentado, la editorial o la sociedad patrocinadora y su dirección.

viii. El director de la revista trabajará con la editorial o sociedad patrocinadora y su dirección a fin de garantizar que los servicios y productos de las partes contratadas, proveedores de servicios y otros entes comerciales necesarios para la publicación adecuada se escojan sobre la base exclusiva de sus méritos.

ix. El director de la revista le advertirá a la editorial o a la sociedad patrocinadora y su dirección de las consecuencias adversas que cabría esperar si se pasara por encima de su criterio profesional, y se asegurará de que las acciones alternas propuestas no menoscaben la integridad editorial.

x. El director de la revista no divulgará información que sea confidencial a no ser que se lo autorice la fuente de la información o que haya acusaciones de conducta indebida cuya naturaleza exija tener acceso a esa información confidencial para fines de una investigación, o que el director de la revista se vea obligado por ley a divulgarla.

xi. El director de la revista deberá abstenerse de usar información confidencial para beneficio personal y deberá dar los pasos necesarios para que esa información no se utilice para beneficio de otras partes.

xii. Si el director de la revista se entera de que estas normas han sido violadas, deberá dar aviso a la editorial o a la sociedad patrocinadora de la revista y a su dirección.

xiii. El director de la revista podría verse llamado a ayudar a la editorial o a la sociedad patrocinadora y su dirección a educar y entrenar a nuevos editores.

\section{RESPONSABILIDADES Y DERECHOS DE LOS ÁRBITROS}

\section{Definición}

Los árbitros son las figuras clave del proceso mediante el cual los resultados de la investigación se traducen en conocimientos. Ese proceso es la publicación, que se lleva a cabo en forma impresa por lo general, aunque la publicación en Internet y otros medios electrónicos está cobrando auge. 
Según F. Peter Woodford en su obra Scientific Writing for Graduate Students [La redacción científica para estudiantes de posgrado], los árbitros son "científicos responsables cuyo afán consiste exclusivamente en lograr que la ciencia avance". En consecuencia, se ofrecen voluntariamente a valorar las virtudes y debilidades del trabajo de un investigador o un grupo de investigadores a petición de la redacción de una revista a la que ha sido presentado dicho trabajo. El propósito del proceso de arbitraje por pares es garantizar la exactitud y el rigor de los trabajos antes de que se diseminen.

El arbitraje científico representa tiempo regalado, sin ninguna recompensa, por personas a quienes el tiempo no les sobra. Es importante, sin embargo, definir los derechos y responsabilidades de este grupo de personas a quienes tanto debe la comunidad científica.

\section{Responsabilidades}

\section{Responsabilidad frente a la comunidad científica}

Los árbitros deben, en primer lugar, cumplir con su responsabilidad simultánea frente a la comunidad científica y a la revista que ha solicitado su aportación. Cumplen con toda su responsabilidad frente a la comunidad científica cuando evalúan rigurosamente los manuscritos en el plazo fijado por la revista.

\section{Responsabilidad frente a los autores}

Los árbitros que aceptan examinar el trabajo de uno de sus pares y emitir comentarios acerca de su exactitud, claridad e importancia, así como su utilidad para el mundo de la ciencia, tienen una gran responsabilidad. La primera consiste en la obligación de tratar al autor y al manuscrito con respeto. Cuando los árbitros están prejuiciados en contra de los investigadores o de su trabajo, deberán negarse a hacer la revisión. Cuando tienen un conflicto de intereses con la investigación o su entidad patro- cinadora, deberán revelárselo al director de la revista o abstenerse de hacer la revisión. Asimismo, si los árbitros no son verdaderos expertos en el campo de investigación del manuscrito que se les ha pedido que revisen, deben declinar la invitación.

En segundo lugar, los árbitros deben hacer una evaluación sincera del valor de la investigación. Una evaluación apropiada abarca un análisis de las virtudes y deficiencias del estudio, sugerencias encaminadas a hacerlo más completo o pertinente, y preguntas específicas que los autores deben contestar para que su estudio goce de mayor aceptación y utilidad entre los lectores a los que va dirigido.

En tercer lugar, los árbitros deben proteger el carácter confidencial de los manuscritos que revisan. Utilizar los datos presentados en esos manuscritos antes de la publicación se considera una conducta inapropiada. Dar a conocer los datos a colegas también lo es, así como reproducir el manuscrito para cualquier fin.

En cuarto lugar, los árbitros no deben usar el proceso de arbitraje como medio para impulsar sus propios intereses académicos pidiéndoles a los autores específicamente que contesten preguntas sobre aspectos que les interesan a los árbitros pero que no son las que el estudio busca contestar.

En quinto lugar, los árbitros deben resistir la tentación de aprovechar sus revisiones para solicitar indirectamente que se citen sus propios trabajos.

\section{Responsabilidad frente a las revistas}

Las responsabilidades de los árbitros frente a las revistas se dividen en varias categorías: velar por la calidad y rapidez de las revisiones y evitar los conflictos de intereses.

Cuando los árbitros reciben invitaciones a revisar manuscritos y es poco probable que las revisiones puedan acabarse dentro del plazo especificado por la revista, deberán declinar la oportunidad de revisar y explicar el motivo. Con esto se cumplen dos objetivos: el manuscrito se procesa sin atraso y la redacción tiene aviso de que los árbitros no deben recibir más manuscritos en el futuro cercano.

Una vez que los árbitros aceptan revisar un manuscrito, es su deber devolver sus comentarios a la redacción en el plazo establecido. Si no les es posible completar la revisión a tiempo, deben avisarle a la redacción y preguntar si deben devolver el manuscrito sin revisarlo o tomarse el tiempo adicional que sea necesario para completar la revisión.

Cuando a un árbitro se le invita a revisar un manuscrito que claramente le plantea un conflicto de intereses, deberá declinar la invitación o divulgar el conflicto. Hay varios tipos de conflictos de intereses, de los cuales el más frecuente es aquel en que hay una relación entre los árbitros y la compañía que patrocinó el trabajo o una compañía que compite con la que patrocinó el estudio que se ha de revisar. Lo más justo es que los árbitros que tienen conflictos de esta naturaleza declinen la invitación a revisar.

Por otra parte, cuando a los árbitros se les invita a revisar manuscritos que contienen manifestaciones de apoyo a posturas contra las cuales se sienten predispuestos, la situación es más compleja y la decisión adquiere un carácter más personal. Por ejemplo, ¿deben los médicos que están a favor de un tratamiento radical en pacientes con determinada enfermedad revisar manuscritos que abogan por el uso de un tratamiento conservador en esos pacientes? En general, estos árbitros deben tomar la determinación por sí solos. El hecho de que la redacción de una revista haya solicitado su opinión acerca de esos manuscritos indica que el director de la revista está buscando revisiones objetivas y probablemente ha elegido a otros árbitros que están a favor de un tratamiento conservador para que haya un equilibrio de opiniones. A la luz de esta posibilidad, los árbitros deben aceptar hacer la revisión si estiman que pueden completarla en el plazo establecido.

\section{Los derechos}

Los árbitros tienen el derecho de esperar que se les dé a conocer el re- 
sultado del proceso de arbitraje de los manuscritos que han revisado. Si se proporciona esa información mientras está en marcha el proceso editorial -como, por ejemplo, cuando un manuscrito se le devuelve al autor para que lo revise- o solamente una vez que se ha tomado una decisión final es un asunto que la revista debe decidir. Pero independientemente del momento en que se haga la notificación, esta debe hacerse. Como servicio educativo y a manera de ayudar a los árbitros a hacer futuras revisiones, es aconsejable mandarle a cada árbitro los comentarios que han emitido sus colegas para que puedan aprender de ellos.

Los árbitros también tienen derecho a esperar que se les agradezca el tiempo que dedican a revisar los manuscritos. El agradecimiento de la redacción puede expresarse de distintas maneras, todas aceptables. Algunas revistas les dan a los árbitros que no están suscritos una breve suscripción a la revista. Muchas publican en la revista una lista de los árbitros que revisaron en determinado año a comienzos del año siguiente. Algunas revistas invitan a los árbitros a una reunión social o educativa, por lo general durante una conferencia.

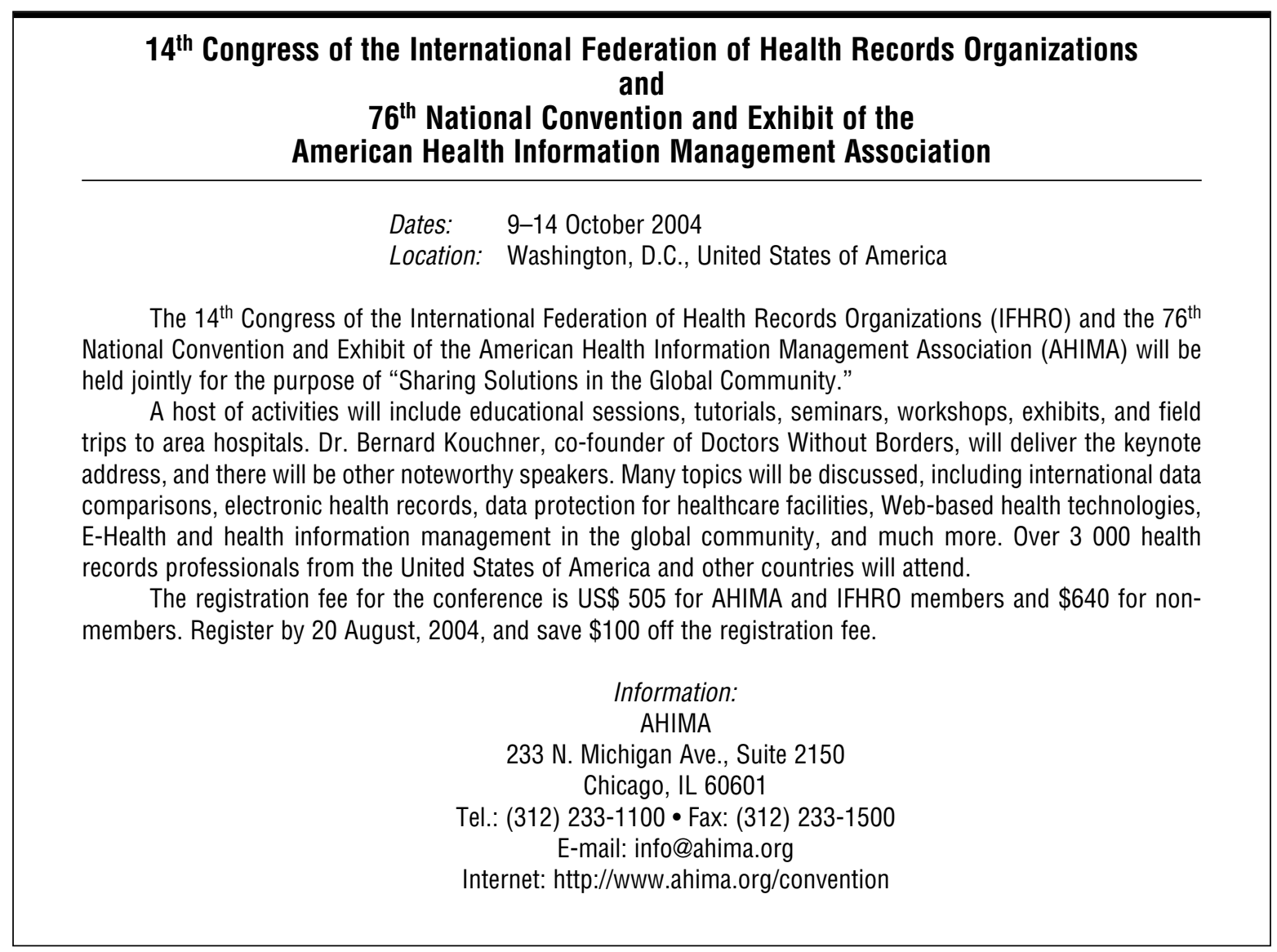

